\title{
Hysterolaparoscopy in the Evaluation and Management of Female Infertility
}

\author{
Y. M. Kabadi ${ }^{1} \cdot$ B. Harsha ${ }^{2}$
}

Received: 17 December 2015/ Accepted: 9 February 2016/Published online: 11 March 2016

(C) Federation of Obstetric \& Gynecological Societies of India 2016

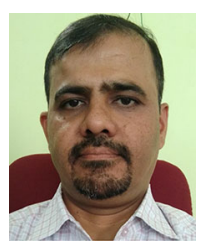

\section{About the Author}

Dr. Y. M. Kabadi graduated from Jawaharlal Nehru Medical College, Belgaum, in the year 2001. He started working at Karnataka Institute of Medical Sciences, Hubli, since 2006. He is currently Assistant Professor in the same institute.

\begin{abstract}
Objective To study the role of hysterolaparoscopy in the evaluation and management of female infertility.
\end{abstract}

Dr. Y. M. Kabadi is a Assistant Professor in Department of OBG at Karnataka Institute of medical Sciences (KIMS, Hubli); Dr. Harsha B is a Postgraduate in Department of OBG at Karnataka Institute of medical Sciences (KIMS, Hubli).

B. Harsha

b.harsh29@gmail.com

Y. M. Kabadi

omkabadi@gmail.com

1 Block 12-2, G-O Quarters, KIMS, Vidyanagara, Hubli 580022, India

2 Department of OBG, Karnataka Institute of Medical Sciences (KIMS), Room No 92, Vivek Hostel, KIMS Campus, Vidyanagara, Hubli, Karnataka 580021, India
Materials and Methods A retrospective study of the 94 case files of all the patients who underwent diagnostic hysterolaparoscopy for infertility between January 2014 to June 2015 in the department of Obstetrics and Gynecology, Karnataka Institute of Medical Sciences, Hubli. These infertile women were confirmed to have normal ovulatory cycles, hormonal assays and seminogram report. Dye studies as well as inspection for abnormal pelvic and intrauterine pathology and necessary therapeutic interventions were done during the procedure. Abnormal pelvic and intrauterine pathology by hysterolaparoscopy were categorized.

Results Out of 94 cases, $53.1 \%$ patients had primary, $17.1 \%$ patients had secondary infertility, and $29.8 \%$ came for tubal recanalization. As a whole pelvic pathology was confirmed in $51.7 \%$ and intrauterine pathology in $18.1 \%$ patients by hysterolaparoscopy. The most common laparoscopic abnormality detected was ovarian pathology $(20.8 \%)$, followed by pelvic inflammatory disease 
(17.5\%). Tubal block comprised $7.7 \%$ whereas distorted uterus by fibroid in $6.6 \%$ and pelvic endometriosis in $5.4 \%$. In hysteroscopy, the incidence of uterine anomaly was $13(13.8 \%)$. Septate uterus is the most common with a mean incidence of approximately 7 (53.8\%).

Conclusion Diagnostic hysterolaparoscopy is an effective diagnostic and therapeutic modality for certain significant and correctable abnormalities in pelvis, tubes and uterus which are missed by other imaging modalities.

Keywords Infertility · Hysteroscopy · Laparoscopy

\section{Introduction}

Infertility is defined as failure to conceive during 1 year of unprotected frequent intercourse. It affects approximately $10-15 \%$ of couples. Leading cause of infertility includes tuboperitoneal disease (40-50\%), ovulatory disorders (30-40\%), uterine factor (15-20\%) and male factor infertility $(30-40 \%)$ [1, 2]. Hysterolaparoscopy is an excellent diagnostic modality to detect hidden pathology in patients without any overt clinical manifestations. Laparoscopy can reveal the presence of peritubal adhesions, periadnexal adhesions, tubal pathology and endometriosis in 35-68 \% of cases even after normal HSG [1]. Diagnostic hysteroscopy is an equally important modality to detect uterine anomalies and other intrauterine pathologies [3].

Keeping this in view, the present study was designed to assess the role of hysterolaparoscopy in the evaluation and management of Infertility.

\section{Methods}

This study was conducted in the Department of Obstetrics and Gynecology in a tertiary care hospital from January 2014 to June 2015 retrospectively. All the infertile patients who underwent diagnostic hysterolaparoscopy in the above mentioned period fulfilling the following criteria were included in this study,

1. Women aged 19-40 years

2. Primary or secondary infertility as per WHO criterion

3. Normal ovulatory cycles and normal serum level of TSH, FSH, LH, prolactin

4. Normal seminogram.

The data collected were demographic factors such as age, duration and type of infertility, base line hormonal profile and records of male evaluation. Intraoperative finding, surgical interventions and complications during procedure were noted. The following parameters such as tubal occlusion, peritubal, periadnexal and dense pelvic adhesions, endometriosis during laparoscopy and abnormality of cervical canal, uterine cavity, bilateral tubal ostium and endometrium during hysteroscopy were noted.

\section{Results}

Out of 94 cases, 50 cases $(53.1 \%)$ had primary infertility, $16(17.1 \%)$ had secondary and $28(29.8 \%)$ came for tubal recanalization.

Majority of cases, $41(43.6 \%)$ belonged to the age group of 18-25 years. Thirty one cases $(33 \%)$ were in the age group of $26-30,17(18 \%)$ belonged to $31-35$ and 5 $(5.4 \%)$ to $36-40$ years (Fig. 1$)$.

Majority of cases, $45(47.8 \%)$ had a married life of 5-10 years. 28 cases $(29.7 \%)$ had a married life under 5 years and 21 cases $(22.3 \%)$ had a married life of $>10$ years (Fig. 2).

Twenty eight patients came for tubal recanalization, out of which 21 cases were favorable and recanalization procedure was done. Seven cases could not be recanalized in view of short lateral ends of the tubes or absent ampullary portions

\begin{tabular}{lcl}
\hline Recanalization statistics & Number & Percentage $(\%)$ \\
\hline Total & 28 & \\
Recanalized & 21 & 75 \\
Not recanalized & 7 & 25 \\
\hline
\end{tabular}

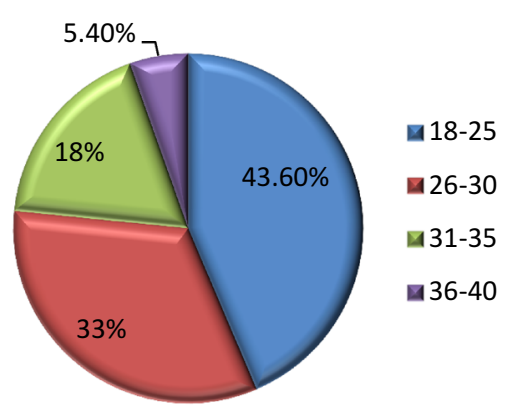

Fig. 1 Age distribution

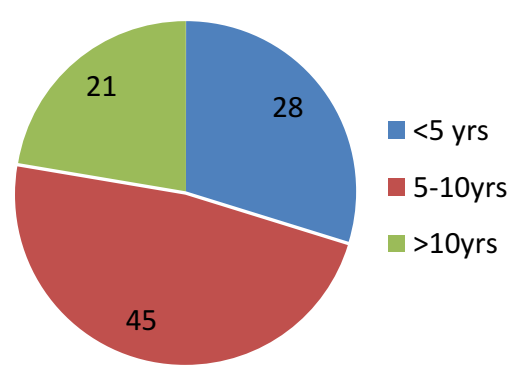

Fig. 2 Married life 
Our study showed pelvic pathology by laparoscopy in $51.7 \%$ of cases, and the results are follows. Ovarian pathology was the most common finding $(20.8 \%)$, followed by pelvic inflammatory disease $(17.5 \%)$. Tubal block comprised $7.7 \%$ whereas distorted uterus by fibroid in $6.6 \%$ and pelvic endometriosis in $5.4 \%$ of infertile cases were diagnosed.

\section{Laparoscopy Findings}

\begin{tabular}{lrl}
\hline Finding & Number $(N=91)$ & Percentage $(\%)$ \\
\hline Normal study & 44 & 48.3 \\
Tubal block & 7 & \\
$\quad$ Unilateral block & 3 & 7.7 \\
$\quad$ Bilateral block & 4 & \\
Polycystic ovaries & 13 & 14.28 \\
Pelvic inflammatory disease & 16 & 17.5 \\
Adhesions & 18 & \\
$\quad$ Flimsy & 13 & 19.7 \\
$\quad$ Dense & 5 & \\
Fibroid uterus & 6 & 6.5 \\
Endometriosis & 11 & 12 \\
$\quad$ Endometriosis of ovary & 6 & 6.6 \\
Pelvic endometriosis & 5 & 5.4 \\
\hline
\end{tabular}

Intrauterine pathology was diagnosed in $18.1 \%$ patients by hysteroscopy.

\section{Hysteroscopy Findings}

\begin{tabular}{lll}
\hline Finding & Number $(N=60)$ & Percentage $(\%)$ \\
\hline Normal study & 43 & 71.6 \\
Uterine anomaly & 13 & 13.8 \\
Polyp/myoma & 6 & 10 \\
Synechiae & 5 & 8.3 \\
\hline
\end{tabular}

The following procedures were carried out as a part of management of infertility. Tubal recanalization, McIndoe vaginoplasty and Strassman's metroplasty were carried out by laparotomy.

\begin{tabular}{lr}
\hline Laparoscopic ovarian drilling & 13 \\
Hysteroscopic septal resection & 6 \\
Laparoscopic myomectomy & 5 \\
Adhesiolysis/synecholysis & 15 \\
Hysteroscopic polypectomy & 5 \\
Tubal recanalization & 21 \\
McIndoe vaginoplasty & 1 \\
Strassman's metroplasty & 1
\end{tabular}

\section{Discussion}

Infertile women with normal ovulatory cycles, seminogram and hormonal profiles have higher possibility of having tuboperitoneal and subtle endometrial pathologies. These women undergo series of procedures like HSG, receiving treatment for timing ovulation with coitus, controlled ovulation stimulation with follicular tracing by transvaginal ultrasound, laparoscopy and hysteroscopy before being referred for ART. Performing hysterolaparoscopy as single step procedure straightway in these patients proves to be more fruitful as therapeutic interventions or early decisions for ART or both can be undertaken simultaneously [4].

Diagnostic hysteroscopy is also a proven method for investigating the cause of female infertility. Uterine pathologies can be the contributing factor for infertility in as many as $15 \%$ of couples seeking treatment [5-8].

Septate uterus is the most common uterine anomaly with a mean incidence of approximately $37.15 \%$ followed by bicornuate uterus approximately $26.13 \%$ and arcuate uterus approximately $21.26 \%$ of uterine anomaly in infertile couple [9]. Our study shows that the incidence of uterine anomaly was $13(13.8 \%)$. Septate uterus is the most common anomaly with a mean incidence of approximately $7(53.8 \%)$ followed by uterine didelphys 2 (15.3\%), MRKH syndrome 1 (7.6\%), Bicornuate uterus 1 (7.6\%), Hypoplastic uterus 1 (7.6\%) and cervical stenosis $1(7.6 \%)$. Septate uterus has been recognized as most common cause associated with highest reproductive failure rates. The reproductive performance of women with an uncorrected septum is rather poor, as $65 \%$ losses occur in the first trimester [10]. Pregnancy outcomes also dramatically improve after surgical correction of septate uterus with $80 \%$ term delivery, $5 \%$ preterm delivery and $15 \%$ pregnancy loss [11].

Our study also revealed myoma and polyp in $6(10 \%)$, synechiae in $5(8.3 \%)$. In infertile patients about $20 \%$ of hysteroscopic examination shows some grade of intrauterine abnormalities [12]. This is at par with our study $18.3 \%(11 / 60)$. In a study comparing hysteroscopy with HSG, the latter showed a false negative rate of $12 \%$ and the complication rate of diagnostic hysteroscopy can be as low as $0.012 \%$ [12, 13]. In our study, we had a complication of hysteroscopic perforation in a case of cervical stenosis which was managed conservatively.

In a retrospective study of 495 infertile women with unexplained infertility, laparoscopy before starting treatment revealed a significant incidence of abnormalities resulting a change in decision [15]. Similarly when patients with unexplained infertility following standard infertility screening tests underwent diagnostic laparoscopy, $21-68 \%$ of these patients was found to have pathologic 
abnormalities which included endometriosis and tubal disease [14, 16, 17]. Our results at laparoscopy and dye studies had shown bilateral tubal patency in $87(92.5 \%)$, bilateral tubal block in $4(4.3 \%)$ and unilateral tubal block in $3(3.2 \%)$ of infertile patients, excluding those who had come for recanalization. In one study at laparoscopy, bilateral tubal patency was demonstrated in $86.67 \%$, bilateral tubal block in $5 \%$ and unilateral block in $8.33 \%$ of patients [9]. In our study, pelvic pathology by laparoscopy was confirmed in $51.7 \%$ of our cases, which was similar to other studies [16, 17]. In the present study, ovarian pathology was the most common finding $(20.8 \%)$, followed by pelvic inflammatory disease $(17.5 \%)$. Tubal block comprised $7.7 \%$ whereas distorted uterus by fibroid in $6.6 \%$ and pelvic endometriosis in $5.4 \%$ of infertile cases were diagnosed.

Thus, diagnostic laparoscopy is the standard means of diagnosing the tubal pathology, peritoneal factors, ovarian factors and uterine factors as cause of infertility. In a comparative study between HSG and laparoscopy done by La Sala et al. for evaluation of tuboperitoneal factors, he had shown a false negative rate $35.5 \%$ and false positive rate of $37.7 \%$ for HSG, and Snowden et al. [18] also in their study obtained the false negative rate of $13 \%$ and false positive rate of $16 \%$ for HSG. HSG showed tubal block in 11 cases, but dye studies showed block in only 7 , a false positive rate of $36.3 \%$.

\section{Conclusion}

As a whole, pelvic pathologies were confirmed in $51.7 \%$ of patients and intrauterine pathologies in $18.1 \%$ of patients by simultaneous diagnostic hysterolaparoscopy. With the view of the low complication rate, minimal time requirements, dealing the abnormal finding therapeutically at the same sitting, a negligible effect in the postoperative course and significant advantage over HSG, hysterolaparoscopy should be considered as a definitive day care procedure for evaluation and treatment of female infertility.

\section{Funding None.}

\section{Compliance with ethical standards}

Conflicts of interest The authors declare no conflict of interest.

Informed consent Informed consent was obtained from all individual participants included in the study.

\section{References}

1. Jahan S. Role of laparoscopy in infertility: review article. BIRDEM Med J. 2012;2:99-103.

2. Howkins J, Bourine GL. The pathology of conception. In: Howkins J, Bourine GL, editors. Shaw's text book of gynaecology. 13th ed. New York: Elsevier; 2004.

3. Hucke J, De Bruyme T, Balan P. Hysteroscopy in infertilitydiagnosis and treatment including falloscopy. Gynecol Obstet. 2000;20:13-20.

4. Begum J, Samal S, Ghose S, et al. Combined hysterolaparoscopy as an early option for initial evaluation of female infertility: a retrospective study of 135 patients. Int J Reprod Contracept Obstet Gynecol. 2015;4:584-8.

5. Wallach EE. The uterine factor in infertility. Fertil Steril. 1972;23:138-58.

6. Brown SE, Coddington C, Schnorr J, et al. Evaluation of outpatient's hysteroscopy, saline infusion hysterosonography and hysterosalpingography in infertile women: a prospective randomized study. Fertil Steril. 2000;74:1029-34.

7. Puri S, Jain D, Puri S, et al. Laparohysteroscopy in female infertility: a diagnostic cum therapeutic tool in Indian setting. Int J App Basic Med Res. 2015;5:46-8.

8. Mooney SD, Milki AA. Effect of hysteroscopy performed in the cycle preceding controlled ovarian hyperstimulation on the outcome of in vitro fertilization. Fertil Steril. 2003;76:637-8.

9. Godinjak Z, Idrizbegovic E. Should diagnostic hysteroscopy be a routine procedure during diagnostic laparoscopy in infertile women? Bosn J Basic Med. 2008;8:44-7.

10. Homer HA, Li TC, Cooke ID. The septate uterus a review of management and reproductive outcome. Fertil Steril. 2000;73:1-4.

11. Zhang E, Zhang Y, Fang L, et al. Combined hysterolaparoscopy for the diagnosis of female infertility: a retrospective study of 132 patients in china. Mater Sociomed. 2014;26(3):156-7.

12. Hourvitz A, Ledee H, Gervaizw A, et al. Should diagnostic hysteroscopy in women with normal hysterosalpingography? Reprod Biomed. 2002;4:256-60.

13. Jansen FW, Vredevooged CB, Van Uzlen K, et al. Complications of hysteroscopy: a prospective multicoated study. Obstet Gynecol. 2000;96:266-70.

14. Corson SL, Cheng A, Gotman JN. Laparoscopy in the normal infertile patient: a question revised. J Am Assoc Gynecol Laparosc. 2000;7:317-24.

15. Tanahatoe SJ, Hompes PG, Lambalk CB. Investigation of the infertile couple: should diagnostic laparoscopy be performed in the infertility workup programme in patients undergoing interuterine insemination? Hum Reprod. 2003;18:8-11.

16. Cundiff G, Car BR, Marshborn PB. Infertile couples with a normal hysterosalpingogram reproductive outcome and its relationship to clinical and laparoscopic finding. J Reprod Med. 1995;40:19-24.

17. Tsuji I, Ami K, Mujazaki A, et al. Benefit of diagnostic laparoscopy for patients with unexplained infertility and normal hysterosalphingography finding. Tohaku J Exp Med. 2009;219:239-42.

18. Vaid K, Mehra S, Verma M, et al. Pan endoscopic approach "hysterolaparoscopy" as an initial procedure in selected infertile women. J Clin Diagn Res. 2014;8(2):95-8. 